\title{
Towards Improving the Quality of Present MAC Protocols for LECIM Systems
}

\author{
Mohammad Arif Siddiqui \\ College of Computer Science and \\ Information Systems \\ Najran University \\ Najran, Kingdom of Saudi Arabia
}

\author{
Shah Murtaza Rashid Al Masud \\ College of Computer Science and \\ Information Systems \\ Najran University \\ Najran, Kingdom of Saudi Arabia
}

\author{
Mohammed Basit Kamal \\ College of Computer Science and \\ Information Systems \\ Najran University \\ Najran, Kingdom of Saudi Arabia
}

\begin{abstract}
Wireless networking system is quickly growing in the field of communication technology due to its usefulness and huge applications. To make the system more effective to the users its lower energy consumption, security, reliability and lower cost issues must be considered under any circumstances. Low energy wireless is exceedingly required because the sensors are frequently located where mains power and network infrastructure are not reliably available. The recent development of Low Energy Critical Infrastructure Monitoring (LECIM) has vast applications including: Water leak detection, Bridge/structural integrity monitoring, Oil \& gas pipeline monitoring, electric plant monitoring, public transport tracking, Cargo container monitoring, Railroad condition monitoring, Traffic congestion monitoring, Border surveillance, Medical alert for at-risk populations and many more. This proposal Low Energy Critical Infrastructure Monitoring (LECIM) is proposed by the Task Group 4k under IEEE P802.15 WPAN. Although many issues related to its quality are involved, but several Media Access Control (MAC) protocols with different objectives were proposed for LECIM. In this research paper, issues related to energy consumption and wastage in LECIM system, energy savings mechanism, relevant energy conscious MAC protocols have been briefly studied and analyzed. Science Direct, Elsevier, Springer, IEEE Explore, Google Scholar and Wiley digital Library databases were used to search for articles related to the existing MAC protocols well suited for LECIM system. Finally, some ideas have been proposed towards developing energy efficient MAC protocol for LECIM applications in order to fulfill and satisfy the major issues of LECIM quality.
\end{abstract}

Keywords-wireless networking; LECIM; IEEE P802.15; WPAN; MAC

\section{INTRODUCTION}

In the practical point of view the usefulness of wireless sensor networking (WSN) system requiring certain criteria including lower energy consumption, security, reliability and lower cost. Low energy wireless is particularly required because the sensors are commonly located where mains power and network infrastructure are not reliably available. The recent development of Low Energy Critical Infrastructure Monitoring (LECIM) has vast applications including: Water leak detection, Bridge/structural integrity monitoring, Oil \& gas pipeline monitoring, electric plant monitoring, public transport tracking, Cargo container monitoring, Railroad condition monitoring, Traffic congestion monitoring, Border surveillance, Medical alert for at-risk populations and many more. Low Energy Critical Infrastructure Monitoring
(LECIM) is proposed by the Task Group 4k under IEEE P802.15 WPAN.

Although many issues related to developing efficient LECIM applications can be summarized like, protection of the sensed data, accessing the shared medium in LECIM network; endpoints sleep time; proper coordination between coordinator and endpoints basically the way of knowing how the endpoints will know that the coordinator wants to send them the data is a challenging job where battery power must work for several years; lack of energy conservation mechanism related to its quality are involved, where most of the existing MAC protocols that support wireless sensor networks can't support these issues properly; formative the status of the channel, in LECIM this is very important because most of the nodes in LECIM system are situated in long distance and the distance among the nodes are also long, the large number of endpoints are also a significant factor. In order to solve this problem the existing contention-based and scheduled-based MAC protocols are not the appropriate solution, it needs to give more attention to solve the above mentioned problems. In this paper, we are expecting to analysis and propose some new ideas for improving MAC protocol for LECIM system, which could fulfill and satisfy the major issues of LECIM quality.

The rest of the paper is structured as follows. In Section II, major challenges, constraints and characteristics of low energy critical infrastructure monitoring; in Section III, sources of energy wastage in LECIM system are studied; in Section IV, we discussed communication patterns and energy consumption measuring system; in Section V, we discussed some mechanisms to reducing energy wastage in LECIM; in Section VI, major MAC requirements for LECIM system are defined, in Section VII, MAC protocol types in applications of LECIM system are briefly discussed; in Section VIII, we proposed some ideas for improving better performance and energy efficiency in MAC for LECIM system. Finally, we concluded and discussed future work in Section IX.

\section{MAJOR CHALlENGES, CONSTRAINTS AND CHARACTERISTICS OF LOW ENERGY CRITICAL INFRASTRUCTURE MONITORING}

Efficient LECIM network including its infrastructure and applications is the important issue for LECIM system. The IEEE TG4K group facilitates single point to several thousands of point's communication for critical infrastructure monitoring containing one coordinator and multiple end points. In this 
process, coordinator is mains powered and end points are battery powered [1] [2]. The main characteristics and challenges for LECIM system is illustrated in the following Table I [3] [4] [5].

TABLE I. CHARACTERISTICS AND CHALLENGES FOR LECIM SYSTEM

\begin{tabular}{|c|c|}
\hline LECIM & Major Characteristics and Challenges \\
\hline \multirow{25}{*}{ 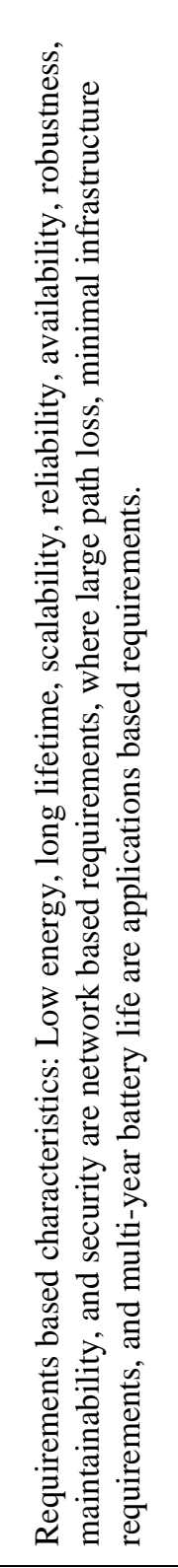 } & $\begin{array}{l}\text { Simultaneous operation for at least } 8 \mathrm{co}- \\
\text { located orthogonal networks }\end{array}$ \\
\hline & Application data rate vary from 1 to $40 \mathrm{kbps}$ \\
\hline & Propagation path loss of at least $120 \mathrm{~dB}$ \\
\hline & $\begin{array}{l}\text { Communication between main-powered coordinator and } \\
\text { large number of endpoints, }>1000 \text { endpoints per mains } \\
\text { powered infrastructure }\end{array}$ \\
\hline & $\begin{array}{l}\text { Asymmetric application data flow. Data flowing from all } \\
\text { or a group of sensors to the central unit and vice versa. }\end{array}$ \\
\hline & Ultra-low maintenance traffic \\
\hline & $\begin{array}{l}\text { Low power consumption, end point need to periodically } \\
\text { go to sleep to conserve energy }\end{array}$ \\
\hline & High channel access efficiency is required \\
\hline & $\begin{array}{l}\text { Primarily outdoor environment with minimal network } \\
\text { infrastructure }\end{array}$ \\
\hline & $\begin{array}{l}\text { Long deployment life with/ without human contact (long } \\
\text { lived infra more than } 10 \text { years life like network carrier's } \\
\text { infra, ease maintained monitoring network, high degree } \\
\text { of freedom to start the monitoring/maintenance business) }\end{array}$ \\
\hline & $\begin{array}{l}\text { Need low energy operation necessary for multi-year } \\
\text { battery life ( }>20 \text { year) }\end{array}$ \\
\hline & Tolerant to data latency \\
\hline & Small, infrequent messages \\
\hline & $\begin{array}{l}\text { Network devices: Coordinator (Collector) typically } \\
\text { mains powered (rarely available). End point devices are } \\
\text { typically battery powered (Battery operation (up to } 20 \\
\text { years), low energy consumption, Low duty cycle). No } \\
\text { mobility of end devices but portability for coordinator. } \\
\text { High network dynamics. }\end{array}$ \\
\hline & Low node density( long range) \\
\hline & Mobility (Asset tracking, Dynamic fail-over) \\
\hline & $\begin{array}{l}\text { Worldwide use(Operates in all regulatory domains, Low } \\
\text { transmit power compliant with international regulations) }\end{array}$ \\
\hline & $\begin{array}{l}\text { Low cost(Low operational cost: unlicensed, lightly } \\
\text { licensed spectrum, Low infrastructure, maintenance, and } \\
\text { system cost, Ease of deployment) }\end{array}$ \\
\hline & $\begin{array}{l}\text { Small device with high applications dependence, with } \\
\text { limited memory, computing, transmitting and limited } \\
\text { energy resources. }\end{array}$ \\
\hline & Must be compatible with existing MAC \\
\hline & $\begin{array}{l}\text { PHY packet size for LECIM: Typical packet duration } \\
\text { "real world" ranges from }<1 \mathrm{~ms} \text { to } \sim 16 \mathrm{~ms}\end{array}$ \\
\hline & Aim to collect the scheduled and event data \\
\hline & $\begin{array}{l}\text { Aim to minimize the network maintenance traffic and } \\
\text { endpoint active durations }\end{array}$ \\
\hline & Aim to collect real time and non-real time data \\
\hline & $\begin{array}{l}\text { Communication patterns: Periodic, event-based and } \\
\text { query-based }\end{array}$ \\
\hline
\end{tabular}

\section{STUDY AND ANALYSIS OF SOURCES OF ENERGY WASTAGE IN LECIM SYSTEM}

Major sources of energy waste of low energy critical infrastructure monitoring (LECIM) based on wireless sensor network (WSN) at medium access communication are depicted in the following Table II.

Sensor node in WSN, the main sources of energy consumption, is divided into three activities including (a) sensing, (b) computation (data processing), and (c) radio operations or communication. Out of those three sources, energy loss due to radio operation or communication for data transmission is the maximum one where energy consumed for radio transmission is directly proportional to distance [6] [7] [8].

Energy waste through communication depends on sensor nodes include theses technological and physical characteristics such as collision, overhearing, control packet overhead, over emitting, idle listening, traffic fluctuation, packet forwarding, excessive state changes of the radio circuit, increased latency [9]-[13]. It's notable that, idle listening is a major cause of energy waste [14].

TABLE II. STUdy AND ANALYSIS OF SOURCES OF ENERGY WASTAGE IN LECIM SYSTEM

\begin{tabular}{|l|l|}
\hline $\begin{array}{l}\text { Source of Energy } \\
\text { Wastage }\end{array}$ & How Energy Is Wasted? \\
\hline Collision & $\begin{array}{l}\text { In any event where multiple frames are received at } \\
\text { the same time, it may damage the resulting signal } \\
\text { and may also cause to loss all information, which } \\
\text { requires re-transmission of collided packets. } \\
\text { Collision results in wasted energy. }\end{array}$ \\
\hline Overhearing & $\begin{array}{l}\text { Message or packets are transmitted to wrong } \\
\text { destination/nodes where its original destination is } \\
\text { other nodes. Overhearing results in wasted energy. }\end{array}$ \\
\hline Idle Listening & $\begin{array}{l}\text { Occurs when the radio of the node is always on and } \\
\text { listening to idle channel or medium even while there } \\
\text { is no transmission. This is another source of wasting } \\
\text { energy. }\end{array}$ \\
\hline Over emitting & $\begin{array}{l}\text { Messages or packets are continuing to transmit even } \\
\text { when the destinations are not ready for receiving } \\
\text { them; as a result, energy for sending the message is } \\
\text { wasted. }\end{array}$ \\
\hline Overhead & $\begin{array}{l}\text { Control data or frames or packets containing } \\
\text { protocol information which are transmitting or } \\
\text { exchanging instead of application data. Energy is } \\
\text { consumed for transmitting and receiving these } \\
\text { frames within medium or channels. This results in } \\
\text { wasted energy. }\end{array}$ \\
\hline
\end{tabular}

\section{STUdY AND ANALYSIS OF SOURCES OF ENERGY WASTAGE IN LECIM SYSTEM}

Several communication models namely broadcast, converge-cast and local gossip in WSN has been used for short and long distance based applications [15]. Transmitting necessary information to all the sensor nodes of the network a broadcast pattern is used by a sink node; in converge-cast pattern a group of sensors communicate to a specific sensor; and the sensors that detect an event communicate with each other locally is defined by local gossip pattern. Energy consumption in communication pattern depends upon its operating states which are divided into four sub-states namely 
transmit state, receive state, idle state, and sleep state. Transmit and receive states are used for sending and receiving data; the default state of WSN is idle state, and sleep state consumes very less energy than any other above mentioned states [16] [17]. Average power consumption of different substates in operating state is defined by the following ratio [18]: Transmit: receive: idle: sleep $=40.25 \%: 29.1 \%: 25.3 \%: 5.4 \%$

Total energy consumption ' $\mathrm{E}$ ' in operating state to transmit ' $\mathrm{k}$ ' bit is illustrated by the following equation [19]:

\section{$E=$ Pactive $\times$ Tactive + Psleep $\times$ Tsleep + Ptransient $\times$ Ttransient + Pidle $\times$ Tidle

Where Pactive, Psleep, Ptransient, Pidle are the power consumption and Tactive, Tsleep, Ttransient, Tidle are the interval or duration of time that a transceiver waits or stays at its active, sleep, transient and idle mode respectively.

\section{MECHANISM to ReducE ENERGY WASTAGE IN LECIM}

In order to increase network's life time and maximizing node in LECIM it's very important to reduce energy waste throughout the system and to enhance the performance of medium access control (MAC) protocol. Different wake up mechanisms could be used to enhance the performance of MAC protocol. Due to the unlimited power consumption of nodes in LECIM and long duration of operation energy efficiency is an important issue. It is generally not possible and practical to recharge or replace the exhausted batteries for sensor nodes in the network. So enhancing the lifetime of network as well as the sensor nodes means enhancing batteries life time.

As discussed earlier the energy consumption in sleep state is lower than idle listening state, so another good mechanism would be to maximize sleep period of the node in MAC layer, while conserving the highest throughput, the lowest latency, and the utmost energy conserving in a WSN [6]. In order to save the transmission energy, several techniques are being used including, energy-aware routing pursuing multi-hop paths, providing time-based medium access control (MAC) by limiting the potential for collisions and minimize the energy consumed in the receiver by turning the radio off when it is idle [20]. Power savings mechanism in MAC layer is classified into three basic classes and they are: effective use of the PHY layer services, optimized media access protocol structure, and useful system design [21].

The power or energy saving mechanisms [22] [23] is illustrated in Table III. Idle listening is the major cause of energy waste, so it is important to introduce suitable MAC protocol which can reduce or prevent energy wastes due to idle listening. Four techniques are being used to avoid idle listening including static sleep scheduling, dynamic sleep scheduling, preamble sampling, and off-line scheduling. Several MAC protocols are already been introduces based on these techniques which are broadly classified into: CSMA, TDMA, hybrid and cross-layer optimization [14]. Using the mechanism mentioned in the following Table IV we can easily measure the performance of energy conscious MAC protocol [24]. In LECIM system the main goal of MAC protocol is to minimize the energy waste due to idle listening, overhearing and collision.

TABLE III. Classification of ENERgy SAVINGS Mechanisms

\begin{tabular}{|l|l|}
\hline $\begin{array}{l}\text { Energy saving } \\
\text { mechanisms }\end{array}$ & Activity \\
\hline $\begin{array}{l}\text { Adaptive duty } \\
\text { cycling protocols }\end{array}$ & $\begin{array}{l}\text { Reduction energy communication waste. Reducing } \\
\text { idle listening through Duty cycling. }\end{array}$ \\
\hline $\begin{array}{l}\text { Wakeup on- } \\
\text { demand protocols }\end{array}$ & $\begin{array}{l}\text { Reduction energy communication waste. Reducing } \\
\text { idle listening. }\end{array}$ \\
\hline
\end{tabular}

TABLE IV. MeChanism To MEASURE THE PERFORMANCE OF ENERGY CONSCIOUS MAC PROTOCOL

\begin{tabular}{|c|c|}
\hline Matrices & Explanation \\
\hline $\begin{array}{l}\text { Energy } \\
\text { consumption per } \\
\text { bit }\end{array}$ & $\begin{array}{l}\text { The total energy consumed } \\
\text { total bits transmitted } \\
\text { define energy efficiency of the sensor nodes. The } \\
\text { unit of energy efficiency is joules/bit. The lesser } \\
\text { the result of ration, the better is the efficiency of a } \\
\text { protocol in transmitting the information in WSN by } \\
\text { satisfying all the major sources of energy waste in } \\
\text { WSN including sleep and idle listening, collisions, } \\
\text { overhearing, control packet overhead, message } \\
\text { passing, etc. }\end{array}$ \\
\hline $\begin{array}{l}\text { Average Delivery } \\
\text { Ratio }\end{array}$ & $\begin{array}{l}\text { The average packet delivery (ratio) is } \\
\frac{\text { the number of packets received over all the nodes }}{\text { the number of packets sent over all the nodes. }}\end{array}$ \\
\hline $\begin{array}{l}\text { Average Packet } \\
\text { Latency }\end{array}$ & $\begin{array}{l}\text { The average time requires by the packets to reach } \\
\text { to the sink node. }\end{array}$ \\
\hline $\begin{array}{l}\text { Network } \\
\text { Throughput }\end{array}$ & $\begin{array}{l}\text { The total number of packets delivered at the sink } \\
\text { node per time unit is defined by network } \\
\text { throughput. }\end{array}$ \\
\hline
\end{tabular}

There are many reasons behind energy consumption in LECIM in WSN as explained earlier. Based on these reasons as mentioned in Table I some approaches are also proposed which are illustrated in Table V below. Approaches those have been proposed in many research papers for wireless systems in general can easily be added to a large variety of WSN MAC protocols. 
TABLE V. APPROACHES TO REDUCE ENERGY CONSUMPTION

\begin{tabular}{|c|c|}
\hline Approaches & Description \\
\hline Reducing Collisions & $\begin{array}{l}\text { CSMA/CA (CSMA/Collisions Avoidance) [25]: to } \\
\text { avoid the collision prior to data transmission } \\
\text { CSMA/CA exchanges RTS (Request To Send) and } \\
\text { CTS (Clear To Send) packets. Due to the small } \\
\text { size of RTS packets, the probability of them } \\
\text { colliding is low. } \\
\text { The improve version of CSMA/CA is MACA } \\
\text { (Multiple Access Collision Avoidance) which adds } \\
\text { a random back-off time before the transmission of } \\
\text { RTS packet to avoid collisions. [26]. } \\
\text { Both the above mentioned techniques aim at } \\
\text { reducing collisions by equally trying to protect all } \\
\text { transmitted packets. }\end{array}$ \\
\hline Reducing Overhead & $\begin{array}{l}\text { CSMA/ARC (Adaptive Rate Control) [26]: it omits } \\
\text { the RTS/CTS exchange technique or avoids using } \\
\text { RTS/CTS altogether for reducing the overhead and } \\
\text { applies a back-off that is shifted according to the } \\
\text { application periodicity while ensuring fairness } \\
\text { between the forwarded traffic and the generated } \\
\text { traffic. }\end{array}$ \\
\hline $\begin{array}{l}\text { Reducing } \\
\text { Overhearing }\end{array}$ & $\begin{array}{l}\text { PAMAS (Power-Aware Multi-Access with } \\
\text { Signaling) [28] is based on MACA. PAMAS uses } \\
\text { separate channel for RTS/CTS exchange where } \\
\text { during transmission an unused node may switch off } \\
\text { its radio to avoid overhearing. }\end{array}$ \\
\hline $\begin{array}{l}\text { Reducing Idle } \\
\text { Listening }\end{array}$ & $\begin{array}{l}\text { The IEEE 802.11 PSM (Power Save Mode) [29] } \\
\text { for BSS (Basic Service Set) is a good approach for } \\
\text { reducing idle listening which ultimately saves } \\
\text { unnecessary energy waste in wireless networks. It } \\
\text { places nodes to sleep as much time as possible for } \\
\text { avoiding and reducing overhearing and overhead. }\end{array}$ \\
\hline
\end{tabular}

\section{MAJOR MAC REQUIREMENTS FOR LECIM SYSTEM}

A different computation and communication infrastructure is provided by WSN which is based on both physical characteristics including the large scale of deployment, inadequate computing capability, and limitations on power consumption; and typical applications including tracking objects or detecting events. As a result, the requirements for the MAC layer of a LECIM system in WSN are clearly different from those for traditional networks [30]. The major requirements for the MAC layer in a LECIM system [31] should be as follows as depicted in Table VI.
TABLE VI. MAC REQUIREMENTS FOR LECIM SYSTEMS

\begin{tabular}{|l|l|}
\hline Objective & MAC Requirements \\
\hline \multirow{2}{*}{} & $\begin{array}{l}\text { Assured and secured link access on low duty } \\
\text { cycle with low energy. }\end{array}$ \\
\cline { 2 - 3 } & Maintain and support to fair access between nodes. \\
\cline { 2 - 3 } & $\begin{array}{l}\text { Avoiding contention-based protocols (control packets } \\
\text { overhead and active sensing of the medium are } \\
\text { performed by these protocols) to minimize contention on } \\
\text { a link (distribute access loads on slotted link) which is } \\
\text { inefficient in terms of energy consumption. }\end{array}$ \\
\cline { 2 - 3 } & Time-stamping (global time synchronization, adjust clock \\
drift with light overhead)
\end{tabular}

\section{MAC PROTOCOL TYPES IN APPLICATIONS OF LECIM SYSTEM}

Low energy consumption is the major issue in any wireless application including LECIM. Therefore designing, implementation and performance of energy efficient MAC 
protocol is a vital issue. Contention-based MAC protocols don't allow communication traffic (flow according to a preset schedule) that's why it's a major concern of large energy consumption, but a time division multiple access (TDMA) based MAC allows communication traffic which reduces energy consumption and extends the life of WSNs. In these time-based MAC enabled WSNs, the nodes can turn off their transmitters or receivers whenever it requires and collision among nodes can also be avoided because each of the nodes has its own time slots which reduce wastage of energy in communication. [32] [33]. The way of prolonging the network/node lifetime in LECIM depends on energy efficient MAC protocols including synchronous MAC protocols and asynchronous MAC protocols. Energy waste is reduced in synchronization because in this mode nodes keep awake only at a specified time and also synchronous protocols maintain a schedule, where, sensor nodes independently schedule their awake period in asynchronous MAC protocols to periodically check the channel while avoiding the synchronization overhead and introducing long latency and excess energy consumption [34]-[36].

There are five categories of MAC protocols specifically designed for WSNs as mentioned below: 1) Scheduling based or contention free or reservation based or cluster based MAC or channel partitioning MAC or controlled access protocol; 2) Collision free MAC protocols; 3) Contention based or channels polling or low power listening or cycled receiver or random access MAC or preamble sampling; 4) Scheduledcontention based MAC protocols or common active period protocol; and 5) Hybrid schemes or protocols.

The three most suitable MAC approaches to designing an energy efficient MAC protocols are Channel Polling (Low power listening-LPL), Scheduled contention, TDMA contention free /cluster-based MAC protocols [37-38].

In the upper portion of both tables, Table VII, Table VIII and Table IX as mentioned bellow present the characteristics of the LPL, schedule-contention, and TDMA mechanisms for wireless sensor network based applications [37-47].

As mentioned, most of the existing MAC protocols are designed for a single channel only, they do not operate on Multi-PHYs simultaneously. Since different bands have different characteristics in terms of data rate, number of subchannels in a particular frequency band/channel, and data prioritization where a good MAC protocol for LECIM should enable reliable operation on MICS, ISM, and UWB etc bands simultaneously, hence MAC transparency has been a hot topic for the MAC designers [48]. Energy saving or energy consumption issue in LECIM MAC is related to synchronous or asynchronous, beacon or preamble, and different periods of wake up and sleep modes. Idle listening dominates the total energy consumption in conventional power management schemes which is based on either periodic wake-up or sleep schedules. Sleep mode power consumption is much less than idle power consumption, which is near to $0.003 \mathrm{~mW}$ [49].

The MAC protocols discussed in Tables (VII-IX) in most of the cases cannot satisfy all the requirements of LECIM. Most of the traditional MAC protocols don't focus on energy conservation a mechanism which is one of the most important requirements of LECIM; they mainly focused on bandwidth utilization and throughput. On other hand contention-based protocols are used to determine the status of the channel supported by, however, this is not always guaranteed in LECIM due to the long distance among the nodes. However scheduled-based protocols provide good solutions for clear channel assessment problems, but due to large number of endpoints and event based traffic these are also not suitable for LECIM. MAC using wakeup radio is also proposed for better communication in LECIM networks.

Large network size, scalability, energy consumption issue including idle listening and delay, long battery lifetime, and security must be the major design issue for constructing any MAC protocol for LECIM.

\section{Proposed IdeAs to EnSURE BetTer PERformance AND ENERGY EFFICIENCY IN MAC FOR LECIM}

a) MAC Protocol with adjustable sensor Sleep Mode.

b) Reduced idle listening based medium access control (MAC) protocol: idle mode of operation should be minimized. network.

c) Periodic wake-up and listen technique for sensor

d) Collision and overhearing avoidance: Interfering nodes go to sleep after they hear an RTS or CTS packet. Collision leads to packet drop, thus reduce throughput and cause energy wastage.

e) Communication and transmission overhearing among sensors must be minimized.

f) Maintaining synchronization: synchronization required for the listen and sleep schemes among neighboring nodes.

g) Proper radio network architecture (diversity) for improving communication reliability in application in wireless sensor network based on heterogeneous and time-varying environmental conditions.

h) Introducing newly evolved communication pattern e.g. communication pattern multicast, in this pattern a sensor sends a message to a specific division or subset of sensors.

i) Introducing energy efficient buffer size of sensors. Packet drop should be prevented due to inadequate or limited buffer capacity causes high energy consumption. topology.

j) Protocol should adapt to changes in network

k) Ensuring reliable transmission with better maintenance of latency. 
TABLE VII. THE MAJOR CHARACTERISTICS OF LOW POWER LiSTENING-LPL MAC Protocol, AND A WidESPREAD STUDY OF THE EXISTING PROTOCOLS IN THE PERSPECTIVE OF ENERGY EFFICIENCY FOR LECIM

\begin{tabular}{|c|c|c|c|c|c|}
\hline \multicolumn{6}{|c|}{ Channel polling or Low Power Listening-LPL } \\
\hline \multicolumn{4}{|c|}{ Channel polling or Low power listening (contention based LPL) } & \multicolumn{2}{|c|}{ Scheduled listening and LPL } \\
\hline \multicolumn{4}{|c|}{$\begin{array}{l}\text { Major reasons of energy wastage in contusion based LPL including: a. node periodically wakes up, b. } \\
\text { turns radio on and c. checks channel. } \\
\text { Result: low energy wasted on idle listening, and high energy wasted on transmissions (long preambles). } \\
\text { Limitation: Overhearing-non-targeted receivers who sample the channel during preamble transmission } \\
\text { have to wait until the end of the preamble to go back to sleep. Energy expenditure is a function of } \\
\text { density as well as traffic load, where entire preamble needs to be sent before data transmission. }\end{array}$} & \multicolumn{2}{|c|}{$\begin{array}{l}\text { In terms of throughput and delay it provides a } \\
\text { good transaction between energy consumption, } \\
\text { complexity and performance. It attains the } \\
\text { benefits of scheduled MAC protocols because of } \\
\text { its simple operation of unscheduled MAC } \\
\text { protocols, as well as the low consumption and } \\
\text { cost-free maintaining and sharing the schedule. }\end{array}$} \\
\hline \multicolumn{6}{|c|}{ Channel polling or low power listening-LPL (contention based) MAC protocols: Adaptability to LECIM } \\
\hline WiseMAC & B_MAC & \begin{tabular}{|l|} 
TICER/ \\
RICER
\end{tabular} & STEM & X-MAC & $\begin{array}{l}\text { A MAC Protocol using } \\
\text { a Wakeup Radio: M.J. } \\
\text { Miller, others }\end{array}$ \\
\hline 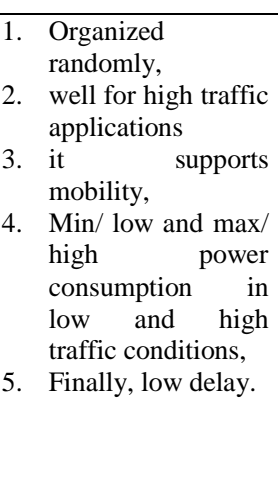 & $\begin{array}{l}\text { 1. Low power } \\
\text { Consumption } \\
\text { on MAC } \\
\text { Protocol. } \\
\text { 2. Nodes wake up } \\
\text { and perform } \\
\text { channel sensing } \\
\text { periodically } \\
\text { 3. Good for high } \\
\text { traffic application } \\
\text { 4. Energy wasted } \\
\text { due to idle } \\
\text { listening and } \\
\text { transmissions (on } \\
\text { link preamble) }\end{array}$ & 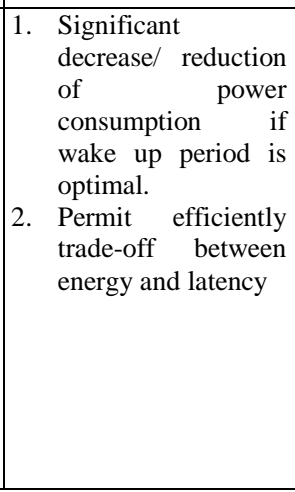 & 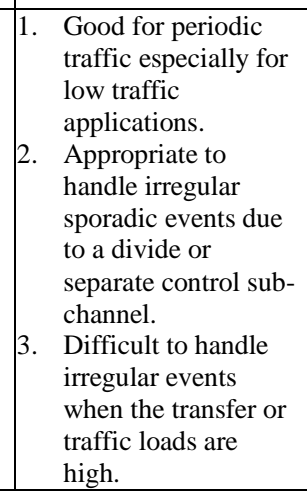 & $\begin{array}{l}\text { 1. } \begin{array}{l}\text { Evade overhearing } \\
\text { problem. }\end{array} \\
\text { 2. It saves energy at } \\
\text { both the transmitter } \\
\text { and receiver } \\
\text { because of its } \\
\text { strobe preamble } \\
\text { approach } \\
\text { 3. It allows for lower } \\
\text { latency }\end{array}$ & $\begin{array}{ll}\text { 1. It reduces energy } \\
\text { consumption. } \\
\text { 2. Outperforms STEM } \\
\text { in energy efficiency } \\
\text { and latency. }\end{array}$ \\
\hline \multicolumn{6}{|c|}{ Proposed protocols for scheduled listening and LPL } \\
\hline \multicolumn{3}{|c|}{ Scheduled Channel Polling MAC (SCP-MAC): Hybrid approach } & \multicolumn{3}{|c|}{ Receiver Initiated MAC: RI-MAC } \\
\hline \multicolumn{3}{|c|}{$\begin{array}{l}\text { 1. It coordinates and synchronizes neighbor's channel polling time. } \\
\text { 2. Reason of energy saving: a short wake up tone wakes up receiver. } \\
\text { 3. Advantage: it is efficient for both unicast and broadcast packets. }\end{array}$} & \multicolumn{3}{|c|}{$\begin{array}{l}\text { 1. It minimizes idle overhearing in dense networks. } \\
\text { 2. Advantages: Sender does the idle listening, and receiver transmits beacons. }\end{array}$} \\
\hline
\end{tabular}

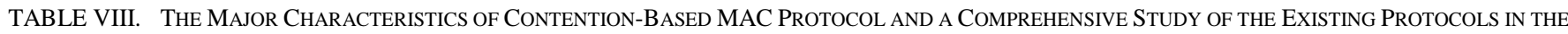
CONTEXT OF ENERGY EFFICIENCY IN LECIM

Scheduled-contention/ contention based MAC Protocol/ Random access MAC

Basic characteristics including:

1. Contention-based MAC such as Carrier Sense Multiple Access/ Collision Avoidance (CSMA/CA) protocols nodes competes for the channel to transmit data.

2. In this scheduled-contention method, nodes must perform clear channel assessment (CCA) before transmission of data.

3. In this mode, if the channel is busy, the node defers its transmission till it becomes idle.

Main reasons of energy (extra) consumption:

1. In a scheduled-contention mechanism, both schemes are combined to gain scalability and to avoid collision during transmission

2. In this mechanism, the nodes become accustomed a common schedule for data communication.

3. During a synchronization period of this mode schedules are exchanged periodically.

4. If two neighboring nodes reside in two different clusters, they keep the schedules of both clusters resulting in extra energy consumption.

5. Listening for full contention period, even listening before transmitting.

6. Although the mechanism is synchronous, but low duty cycle nodes don't need frequent synchronization/exchange of schedules in wireless sensor network based applications.

\begin{tabular}{|c|c|c|c|c|}
\hline \multicolumn{5}{|c|}{ Existing contention-based MAC protocols: Adaptability to LECIM } \\
\hline Sensor-MAC (S-MAC) & Pattern-MAC (PMAC) & Timeout MAC(T-MAC) & $\begin{array}{l}\text { Dynamic Sensor-MAC } \\
\text { (DSMAC) }\end{array}$ & $\begin{array}{l}\text { Sleep Scheduled Delay } \\
\text { Efficient (DESS) }\end{array}$ \\
\hline $\begin{array}{l}\text { Major issues including: } \\
\text { 1. Low throughput, } \\
\text { overhearing and collision } \\
\text { may cause if the packet is } \\
\text { not intended to listening } \\
\text { node. } \\
\text { 2. Good for high traffic }\end{array}$ & 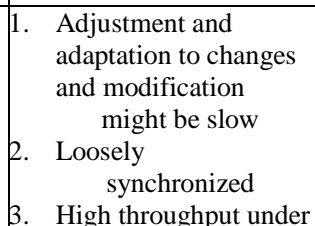 & $\begin{array}{l}1 . \\
\text { version of SMAC. } \\
2 . \text { It does not use } \\
\text { fixed active period. But it } \\
\text { has the capability to } \\
\text { abridge or shorten the } \\
\text { active period if the channel }\end{array}$ & $\begin{array}{l}\text { 1. } \quad \text { Better delay } \\
2 . \\
\text { dynamic sleep scheme to } \\
\text { save energy. }\end{array}$ & $\begin{array}{l}\text { 1. Enhanced or improved } \\
\text { delay for the topology } \\
\text { like: grid and tree } \\
\text { 2. Random or arbitrary } \\
\text { topology is not } \\
\text { guaranteed even by better } \\
\text { delay. }\end{array}$ \\
\hline
\end{tabular}




\begin{tabular}{|c|c|c|c|}
\hline $\begin{array}{l}\text { applications. } \\
\text { 3. Appropriate for applications } \\
\text { where throughput is not a } \\
\text { principal concern e.g. in- } \\
\text { body medical applications. }\end{array}$ & $\begin{array}{l}\text { heavy traffic. } \\
\text { 4. Good for delay-sensitive } \\
\text { applications. }\end{array}$ & $\begin{array}{l}\text { is idle for a short time. } \\
3 . \\
\text { in the case of data, the node } \\
\text { remains active till data } \\
\text { reception or until the active } \\
\text { period ends. } \\
4 \text {. In this mode better } \\
\text { delay, and gives better } \\
\text { result under variable load, } \\
\text { because packets are sent in } \\
\text { burst, } \\
4 . \\
\text { high traffic applications. } \\
5 . \\
\text { may lose synchronization } \\
\text { due to its early sleep } \\
\text { problems. }\end{array}$ & $\begin{array}{l}\text { 3. This mode is loosely and } \\
\text { insecurely synchronized. }\end{array}$ \\
\hline
\end{tabular}

TABLE IX. THE MAJOR CHARACTERISTICS OF SCHEDUlED-BASED MAC PROTOCOL AND A COMPREHENSIVE AND WIDESPREAD STUDY OF THE EXISTING PROTOCOLS IN THE CONTEXT OF ENERGY EFFICIENCY FOR LECIM

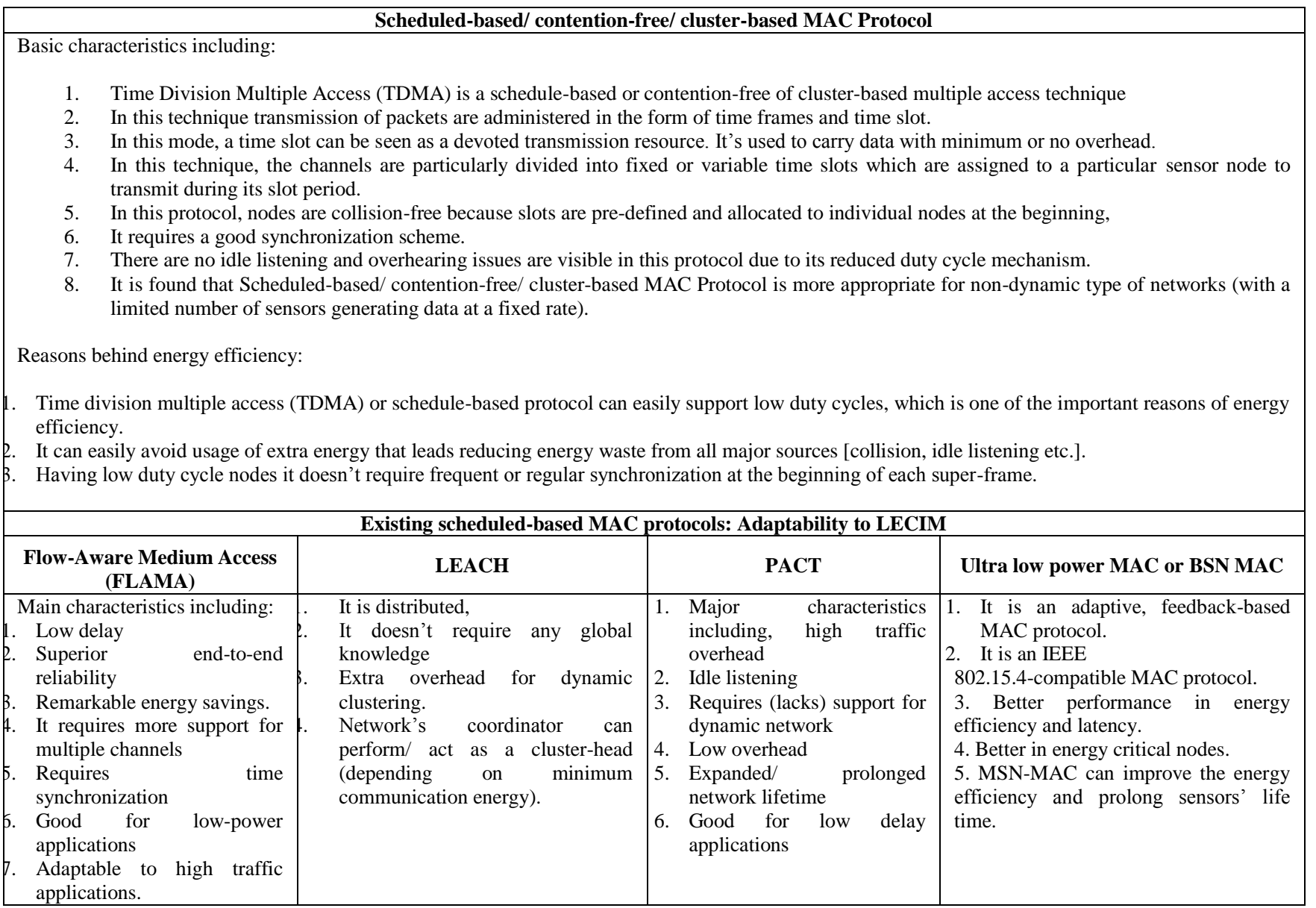

\section{CONCLUSION}

In this paper, the researchers have presented issues related to energy consumption and wastage in LECIM system, energy savings mechanism. We have also studied and analyzed LECIM relevant energy conscious MAC protocols. Finally, some recommendations have been proposed for developing energy efficient MAC protocol to satisfy the major issues of LECIM quality.

\section{ACKNOWLEDGEMENT}

This research was supported by Najran University, Kingdom of Saudi under the grant number ESCI/13/27.

\section{REFERENCES}

[1] Seong-Soon Joo, Jong-Arm Jun, Cheol-Sig Pyo, MAC Proposal for Low-Energy Wide Area Monitoring, 15-11-0597-00-004k-lecim-macproposal-for-tg4k.ppt

[2] P. Kinney, "LECIM Call for Proposals, IEEE P802.15-11-0147-02-004k 2011, https://mentor.ieee.org/802.15/documents 
[3] David Howard, SG Low Energy, Critical Infrastructure Monitoring (LECIM) Project Draft PAR, 15-10-0756-09-leci-sglecim-par-draft.docx

[4] Yang Yang, Xiang Wang, Heqing Huang, Jie Shen, Tao Xing, Haitao Liu, Betty Zhao' 'Low Energy MAC Proposal for TG4k_WSNIRI', 1511-0596-00-004k-wsniri-low-energy-mac-proposal-for-tg4k.ppt

[5] Kyungsup Kwak, Jaedoo Huh, Hyung Soo Lee, M. Al Ameen, Niamat Ullah, M.S. Chowdhury, 'A Dynamic Framed Slotted ALOHA protocol for LECIM Networks', 15-11-0486-03-004k-inha-etri-tg4kproposal.pptx

[6] I. Demirkol, C. Ersoy, and F. Alagoz, MAC Protocols for Wireless Sensor Networks: A Survey, IEEE Communication Magazine, Vol. 44, Issue 4, pp.115-121, April 2006.

[7] S. Singh and C.S. Raghavendra, "PAMAS: Power Aware Multi-Access protocol with Signaling for Ad Hoc Networks", ACM Computer Communications Review, July1998.

[8] P. Havinga, G. Smit, "Energy-efficient TDMA medium access control protocol scheduling," in the Proceedings of the Asian International Mobile Computing Conference (AMOC 2000), November 2000.

[9] Sai Anand Gopalan, Jong-Tae Park, Energy-Efficient MAC Protocols for Wireless Body Area Networks: A Survey, School of Electronics Engineering, Kyungpook National University Daegu, South Korea

[10] W. Ye, J. Heidemann, and D. Estrin, "An energy-efficient MAC protocol for wireless sensor networks," in INFOCOM, 2002, pp. 15671576.

[11] Sana Ullah *, Bin Shen, S.M. Riazul Islam, Pervez Khan, Shahnaz Saleem and Kyung Sup Kwak, A Study of MAC Protocols for WBANs, Sensors 2010, 10, 128-145; doi:10.3390/s100100128

[12] Kyung Sup Kwak, WBAN MAC: Technology and Proposal, UWB Wireless Communications Research Center Inha University, Incheon, Korea, 2009-04-16

[13] ShihHeng Cheng and ChingYao Huang, Power Model for Wireless Body Area Network, Biomedical Circuits and Systems Conference, 2008. BioCAS 2008. IEEE, pp. 1-4.

[14] COMPARISON OF CSMA BASED MAC PROTOCOLS OF WIRELESS SENSOR NETWORKS, Himanshu Singh and Bhaskar Biswas

[15] S.S. Kulkarni, "TDMA Services for Sensor Networks", Proceedings of 24th International Conference on Distributed Computing Systems Workshops, 23-24 March 2004, pp. 604-09.

[16] Stemm, M., and R. H Katz, "Measuring and reducing energy consumption of network interfaces in hand-held devices", IEICE Transactions on Communications, Special Issue on Mobile Computing, E80-B(8), August 1997, pp.1125-1131.

[17] Chen, B., K. Jamieson, H. Balakrishnan, and R. Morris, "Span: An energy efficient coordination algorithm for topology maintenance in ad hoc wireless networks", ACM Wireless Networks Journal, vol.8 (5), September 2002, pp.481-494.

[18] N. K. Ray and A. K. Turuk, "A Review on Energy Efficient MAC Protocols for Wireless LANs," in Fourth International Conference on Industrial and Information Systems, ICIIS 2009, Sri Lanka, 2009.

[19] www.scalablenetworks.com/publications/documentation.

[20] S. Singh and C.S. Raghavendra, "PAMAS: Power Aware Multi-Access protocol with Signaling for Ad Hoc Networks", ACM Computer Communications Review, July1998.

[21] Hagen Woesner, adam Wolisz, Power saving mechanism in emerging standards for wireless LANs: the MAC level perspective, IEEE PCS, 2001.

[22] Vivek Jain, Ratnabali Biswas, Dharma P. Agrawal: Energy-Efficient and Reliable Medium Access in Sensor Networks. WOWMOM 2007: 1-8.

[23] V. Rajendran, J. J. Garcia-Luna-Aceves and K. Obraczka, "EnergyEfficient Application-Aware Medium Access for Sensor Networks", IEEE International Conference on Mobile Adhoc and Sensor Systems, November 2005. FLAMA

[24] Salman Faiz Solehria, Sultanullah Jadoon, Medium Access Control Protocol for Wireless Sensor Network - a Survey, International Journal of Video \& Image Processing and Network Security IJVIPNS-IJENS Vol: 11 No: 03
[25] H. Takagi and L. Kleinrock, "Throughput Analysis for Persistent CSMA Systems," IEEE Transactions On Communications, vol. 33, no. 7, pp. 627-638, July 1985.

[26] P. Karn, "MACA - A New Channel Access Method for Packet Radio," in 9th ARRL Computer Networking Conference, London, Ontario, Canada, 1990.

[27] A. Woo and D. Culler, "A Transmission Control Scheme for Media Access in Sensor Networks," in ACM Mobicom, Rome, Italy, July 2001.

[28] S. Singh and C. S. Raghavendra, "PAMAS - power aware multi-access protocol with signaling for ad hoc networks," ACM SIGCOMM Computer Communication Review, vol. 28, no. 3, pp. 1048-1057, 1998

[29] I. C. Society, 802.11 IEEE Standard for Information technology Telecommunications and information exchange between systems - Local and metropolitan area networks - Specific requirements. Part 11: Wireless LAN Medium Access Control (MAC) and Physical Layer (PHY) Specifications, IEEE Std., 12 June 2007.

[30] Ruizhong Lin, Zhi Wang, and Youxian Sun, Energy Efficient Medium Access Control Protocols for Wireless Sensor Networks and Its State-ofArt, 0-7803-8305-2/04/\$20.00 @2004 IEEE

[31] Shah Murtaza Rashid Al Masud. Article: Study and Analysis of Scientific Scopes and Issues towards Developing an Efficient LECIM. International Journal of Computer Applications 74(6):46-56, July 2013. Published by Foundation of Computer Science, New York, USA

[32] S. Singh and C.S. Raghavendra, "PAMAS: Power Aware Multi-Access protocol with Signaling for Ad Hoc Networks", ACM Computer Communications Review, July1998.

[33] [13] P. Havinga, G. Smit, "Energy-efficient TDMA medium access control protocol scheduling," in the Proceedings of the Asian International Mobile Computing Conference (AMOC 2000), November 2000.

[34] A. Barroso, U. Roedig, and C. Sreenan, " $\mu$-MAC: an energy-efficient medium access control for wireless sensor networks", Wireless Sensor Networks, 2005. Proceedings of the Second European Workshop on 24 Jan.-2 Feb. 2005 Page(s): $70-80$.

[35] P.C. Nar and E. Cayirci, "PCSMAC: a power controlled sensor-MAC protocol for wireless sensor networks", Wireless Sensor Networks, 2005. Proceedings of the Second European Workshop on 24 Jan.-2 Feb. 2005 Page(s):81 - 92.

[36] C. K. Nguyen and A. Kumar, "An energy-aware medium-access-control protocol with frequent sleeps for wireless sensor networks", Computers and Communications, 2005. ISCC 2005, Proceedings, and 10th IEEE Symposium on 27-25 June 2005 Page(s):386 - 391.

[37] V. Rajendran, J. J. Garcia-Luna-Aceves and K. Obraczka, "EnergyEfficient Application-Aware Medium Access for Sensor Networks", IEEE International Conference on Mobile Adhoc and Sensor Systems, November 2005. FLAMA

[38] Hind Chebbo, Literature Review of Energy Efficient MAC in WSN/BAN, IEEE P802.15 Working Group for Wireless Personal Area Networks (WPANs), May, 2008.

[39] Polastre, J.; Hill, J.; Culler, D. Versatile low power media access for wireless sensor networks. In Proceedings of the 2nd International Conference on Embedded Networked Sensor Systems, New York, NY, USA, 2004; pp. 95-107.

[40] Schurgers, C.; Tsiatsis, V.; Srivastava, M.B. STEM: Topology management for energy efficient sensor networks. In Proceedings of Aerospace Conference, Manhattan Beach, CA, USA, 2004; Volume 3, pp. 3-1099-3-1108.

[41] Dam, V.T.; Langendoen. K. An adaptive energy-efficient mac protocol for WSNs. In Proceedings of the 1st ACM Conference on Embedded Networked Sensor Systems (Sen-Sys), Los Angeles, CA, 2003; pp. 171180.

[42] Khan, N.P.; Boncelet, C. PMAC: Energy efficient medium access control protocol for wireless sensor networks. In Proceedings of IEEE Military Communications Conference, Washington, DC, USA, 2006; pp. $1-5,23-25$.

[43] Lu, G.; Krishnamachari, B.; Raghavendra, C. An Adaptive EnergyEfficient and Low-Latency MAC dor Data Gathering in Sensor Networks. In Proceedings of the 4th International Workshop on 
Algorithms for Wireless, Mobile, Ad Hoc and Sensor Networks, Santa $\mathrm{Fe}$, Mexico, 2004.

[44] Rajendran, V.; Garcia-Luna-Aveces, J.J.; Obraczka, K. Energy-efficient, application-aware medium access for sensor networks. In Proceedings of IEEE Mobile Adhoc and Sensor Systems Conference, Washington, DC, USA, 2005; p. 8630.

[45] Heinzelman, W.R.; Chandrakasan, A.; Balakrishnan, H. Energy-efficient communication protocol for wireless microsensor networks. In Proceedings of the 33rd Annual Hawaii International Conference on System Sciences, Maui Kula, HI, USA, 2000.
[46] Younis, O.; Fahmy, S. Heed: A hybrid, energy-efficient, distributed clustering approach for adhoc sensor networks. IEEE Trans. Mob. Comp. 2004, 3, 366-379.

[47] R. Venkateswari, S. Subha Rani, P. Gowtham Reddy: Efficient MAC protocol for Wireless Body Area Nwtworks-A survey, GJCST, Volume 11, Issue 8, Version1.0, May 201, USA.

[48] Index of Bureaus. Available online: http://www.fcc.gov/Bureaus/ (accessed on 16 August 2009).

[49] Niamat Ullah, ${ }^{*}$ Pervez Khan, and Kyung Sup Kwak: A Very Low Power MAC (VLPM) Protocol for Wireless Body Area Networks, Graduate School of Information \& Communication Engineering, Inha University, 253 Yonghyun-dong, Nam-gu, Incheon 402-751, Korea. 